\title{
Da manufatura moderna à grande indústria: delimitação empírica da mudança técnica no setor de autoveículos no Brasil (1996-2017)
}

\author{
ELCEMir PaÇo Cunha \\ Lara nora portugal Penna ${ }^{1}$ \\ LEANDRO THEODORO GUEDES ${ }^{2}$ \\ ${ }^{1}$ Universidade Federal de JUIZ de Fora (UFJF), JUIZ DE Fora - MG, BRASIL \\ 2 UNIVERSIDAde FEDERAL DE VIÇOSA (UFV), VIÇOSA - MG, BRASIL
}

\section{Resumo}

O objetivo do presente artigo é delimitar empiricamente a inflexão do princípio na base técnica para o setor de autoveículos brasileiro, demarcando o período com maior probabilidade de ocorrência da transição entre manufatura moderna e grande indústria. Realizou-se a pesquisa com a hipótese de que essa transição ocorreu tardiamente no Brasil, não antes dos anos 2000. Para verificá-la, trabalhou-se com análise de fatores econômicos ligados às inversões de capital e à modificação da força de trabalho no período entre 1996 e 2017 . A pesquisa não apenas confirmou a hipótese, como também delimitou a ocorrência da transição entre 2000 e 2004.

Palavras-chave: Mudança técnica. Autoveículos. Brasil.

From modern manufacture to large industry: empirical delimitation of technical change in the automotive sector in Brazil (1996-2017)

\section{Abstract}

This article aims to empirically delimit the inflection of the principle on the technical basis for the Brazilian automobile sector, marking the period with the greatest probability of the transition between modern manufacturing and machine system. The research tested the hypothesis that this transition took place late in Brazil, not before the 2000s, analyzing the economic factors related to capital inversions and the change in the workforce in the period between 1996 and 2017. The research confirmed the hypothesis and also delimited the occurrence of the transition between 2000 and 2004.

Keywords: Technical change. Automobile. Brazil.

\section{De la manufactura moderna a la gran industria: delimitación empírica del cambio técnico en el sector automotor} en Brasil (1996-2017)

\section{Resumen}

El propósito de este artículo es delimitar empíricamente la inflexión del principio en la base técnica para el sector automotor brasileño, demarcando el período con mayor probabilidad de ocurrencia de transición entre la manufactura moderna y la gran industria. La investigación se Ilevó a cabo con la hipótesis de que esa transición ocurrió tardíamente en Brasil, no antes de la década de 2000. Para verificar esta hipótesis, se trabajó con el análisis de factores económicos relacionados con las inversiones de capital y la modificación de la fuerza laboral en el período entre 1996 y 2017. La investigación no solo confirmó la hipótesis, sino que también delimitó la ocurrencia de la transición entre 2000 y 2004.

Palabras clave: Cambio técnico. Vehículos automotores. Brasil. 


\section{INTRODUÇÃO}

Um dos elementos centrais do estudo da dinâmica econômica e da transformação das empresas é a mudança técnica (Acemoglu \& Restrepo, 2019; Dosi, Teece \& Chytry, 2005; Frey, 2019), conforme sancionam diferentes correntes entre marxistas, neoclássicas, veblenianas, schumpterianas etc. (Pelaez \& Szmrecsányi, 2006).

É comum na literatura a hoje clássica distinção entre o período da produção em massa, particularmente representada pela montagem de automóveis após 1908, e o período seguinte aos anos de 1970, com a chamada revolução da informação. Enquanto a produção em massa teria se baseado na mecanização, o período posterior a 1970 constataria a microeletrônica como tal fundamento (Perez, 1985). Esses períodos se distinguiriam pela alteração do paradigma técnico-econômico vigente, como mencionou Perez (2011). Outras tradições teóricas empregam terminologia diferenciada ("terceira revolução tecnológica", "novo padrão de acumulação", "pós-fordismo" etc.), porém com propósito semelhante de distinguir padrões históricos.

Essa forma de análise, entretanto, generaliza esses padrões em que a diferença do desenvolvimento entre setores fica obscurecida, embora seja relevante destacá-la (Dosi \& Orsenigo, 1988). Em vez de paradigmas, passa a ser necessário distinguir os princípios que fundamentam determinadas bases técnicas em setores específicos, possibilitando a identificação da mudança técnica com maior precisão. $\mathrm{O}$ argumento do presente artigo é que as categorias desenvolvidas adiante - manufatura moderna e grande indústria - capturam melhor essa transição entre princípios da base técnica, sobretudo para o caso destacado do setor de autoveículos no Brasil.

A pesquisa sobre as transformações ocorridas no setor de autoveículos - montagem de carro, caminhão e ônibus - no país acumulou muitas páginas desde o início dos anos de 1980. Acerca do fato das mudanças, ergueram-se investigações que criaram obstáculos ao avanço do conhecimento científico sobre o assunto (Tumolo, 2001). Muitas aproximações a partir daquela década, incluindo as realizadas na administração (e.g., Faria, 1992), consideraram tais transformações com êxitos variados. A preocupação do fim da década de 1980, de talhe "regulacionista", acerca dos efeitos da microeletrônica sobre o processo de trabalho como expressão da transição entre fordismo e neofordismo, restou inconclusiva. Nas duas décadas seguintes, desenvolveu-se o interesse sobre a "reestruturação produtiva" - consumada na década de 1990 ou no início dos anos 2000 -, em particular com respeito às conexões entre a organização do trabalho de tipo toyotista e as amplas modificações sindicaltrabalhistas a reboque da chamada "acumulação flexível". No conjunto, observa-se tanto o enfraquecimento gradativo do interesse pela mudança técnica propriamente dita quanto seu deslocamento para a organização do trabalho.

Essas aproximações investigativas deixaram pelo menos dois aspectos lacunares relacionados: a mudança técnica stricto sensu na base produtiva e a delimitação temporal precisa dessa mudança. Na medida em que a primeira ficou subordinada às preocupações com a organização do trabalho, sua identificação na temporalidade histórica também ficou prejudicada. Portanto, a despeito de suas contribuições, fordismo, neofordismo e reestruturação produtiva são formas limitadas de aproximação conceitual à problemática da mudança técnica. Fica patente a necessidade científica de retomar o ângulo da introdução de elementos, como foi o caso da microeletrônica e da robótica, os quais atuaram sobre os princípios técnicos que formam a base produtiva daquela indústria em particular. Torna-se mais relevante ajustar a análise desses eventos levando-se em conta a nova onda de modificações técnicas já postas no horizonte imediato.

A problemática do presente artigo, portanto, está circunscrita à investigação da mudança do princípio da base técnica na montagem de autoveículos no Brasil. Disso se desdobra o objetivo de delimitar empiricamente no tempo a inflexão desse princípio na base técnica. A aproximação dessa mudança requer os traçados diferenciais essenciais em lugar da conceituação fordismo, reestruturação - que, como dito, tendencialmente se desloca para a dimensão da organização do trabalho. Como será explicitado adiante, a reprodução do movimento objetivo de mudança do princípio da base técnica no setor e no país em tela revela a diferença e a transição entre manufatura moderna e grande indústria como categorias caracterizadoras mais decisivas, isso porque elas expressam adequadamente a diferença, a transição e a eventual inflexão objetiva dos princípios sobre os quais se arqueiam diferentes bases técnicas.

A hipótese de trabalho inicial da pesquisa, colhida de evidências da literatura, foi que a transição da manufatura moderna para a grande indústria no setor de autoveículos ocorreu no Brasil tardiamente em relação às economias centrais, após o ano 2000. Para verificá-la, realizou-se uma investigação que se enquadra no âmbito de interface entre a gestão da tecnologia e a economia da tecnologia, considerando a variação temporal entre 1996 e 2017 de fatores que descrevem a modificação quantitativa e qualitativa dos capitais aplicados e da força de trabalho. Como explicitado adiante na seção metodológica, 
trata-se de uma pesquisa indireta da mudança técnica com base nas perturbações observáveis em determinados fatores. As fontes principais dos dados foram a Associação Nacional de Produtores de Veículos Automotores (Anfavea), o Instituto Brasileiro de Geografia e Estatística (IBGE) e a Relação Anual de Informações Sociais (Rais).

A contribuição fundamental da pesquisa é de ordem teórica, metodológica e empírica. Em termos teóricos, a diferenciação desenvolvida na seção a seguir, entre manufatura moderna e grande indústria, corrige as dificuldades conceituais e estabelece uma teoria mais ajustada às diferenças entre modalidades de bases técnicas. De forma metodológica, o isolamento da base técnica para análise permite delimitar com maior rigor a mudança do princípio que a fundamenta. Em termos empíricos, supre-se a lacuna da identificação temporal da mudança de tal princípio.

O artigo está dividido em 4 seções, além desta Introdução. A primeira apresenta a fundamentação teórica para delimitação da base técnica e as diferenças entre manufatura e grande indústria como categorias mais ajustadas. A segunda contém o detalhamento de aspectos e procedimentos metodológicos. A terceira apresenta a análise dos dados, procurando delimitar a inflexão no esforço de verificação da hipótese de trabalho. A quarta e última contém as considerações finais do artigo.

\section{FUNDAMENTAÇÃO TEÓRICO-HISTÓRICA}

É preciso delimitar as categorias teóricas fundamentais da análise provenientes da dinâmica histórica (Kabat, 2005; Marx, 2011, 2013; Moraes, 1991, 2003; Paço Cunha, 2019; K. Williams, Cutler, J. Williams \& Haslam, 1987): diferenciação, unidade e relação entre base técnica e organização do trabalho, tendo como norte a necessidade metodológica de isolamento da base técnica; e diferenciação e transição entre manufatura e grande indústria.

Entende-se por base técnica a "especificidade dos meios empregados em termos de capital fixo: instrumentos, ferramentas, maquinaria. Essa base técnica se altera de forma incremental ou radical. Enquanto a primeira aperfeiçoa meios já existentes, a segunda altera o próprio princípio fundamental em que determinado processo de produção se assenta" (Paço Cunha, 2019, p. 89). Isolando a segunda modalidade de alteração, trata-se de considerar, em primeiro lugar, a modificação do padrão geral, e não de ignorar as modificações incrementais que se acumulam - as quais eventualmente condicionam a modificação daquele padrão. Aqui cabe a importante diferença, retomada adiante, entre mecanização como introdução de elementos como nova força motriz, esteiras, linhas puxadas etc., e automação, com a introdução de um único maquinismo que opera todas as funções da produção ou a articulação de um sistema de máquinas parciais diferentes.

Por seu turno, a organização do trabalho é uma "dada combinação dos diferentes indivíduos na relação com a operação dos meios [...] variando a forma e o grau de divisão do trabalho e especialização" de modo que certas inovações organizacionais "podem igualmente assumir forma incremental ou mais substantiva" (Paço Cunha, 2019, p. 89). De uma simples nova divisão do trabalho ao taylorismo, vê-se o espectro dessas modificações. O fordismo, adicionalmente, continua sendo uma modificação da organização do trabalho a despeito de um grau superior de mecanização que, no entanto, diz respeito aos avanços da base técnica sobretudo quanto ao transporte das partes e dos componentes entre etapas de montagem. $O$ toyotismo se iguala como forma de organização do trabalho numa base técnica também mecanizada. Taylorismo, fordismo e toyotismo, portanto, são possíveis sob uma mesma base técnica, a despeito do grau de mecanização.

É preciso sublinhar os aspectos essenciais desta tríade - taylorismo, fordismo e toyotismo - como caracterização de formas de organização do trabalho e, por decorrência, dos seus vínculos predominantes à força de trabalho (trabalho vivo). Nessa direção, o "taylorismo caracteriza-se como uma forma avançada de controle do capital (com o objetivo de elevar a produtividade do trabalho) sobre os processos de trabalho nos quais o capital dependia da habilidade do trabalhador", operando principalmente através do "controle de todos os tempos e movimentos do trabalhador, ou seja, do controle (...) de todos os passos do trabalho vivo" (Moraes, 1991, p. 34, grifos nosso). Por sua vez, o "fordismo, enquanto processo de trabalho organizado a partir de uma linha de montagem, deve ser entendido como desenvolvimento da proposta taylorista", considerando o sentido de que se procura o "auxílio dos elementos objetivos do processo (trabalho morto), no caso a esteira, para objetivar o elemento subjetivo (trabalho vivo)" (Moraes, 1991, p. 35, grifos nosso). Em sua especificidade comparativa, entende-se toyotismo ou "ohnoísmo como uma forma particular de lastrear a produção em massa no trabalho vivo, o que, por sua vez, adveio do fato de significar uma mudança organizacional, e não tecnológica" (Moraes, 2003, p. 108). Desse modo, pode-se caracterizar o "ohnoísmo como produção em massa flexível igualmente alicerçada no trabalho vivo" (Moraes, 2003, p. 109). 
É possível extrair uma teoria para o nexo entre base técnica e organização do trabalho considerando o movimento histórico e que não se exprime por simples relação de função, como foi mais comum em algumas tradições (e.g., Woodward, 1980). Para o presente artigo, o propósito dessa teoria é decantar, por procedimento abstrativo, a base técnica para análise.

Com efeito, a base técnica forma o plano das condições objetivas de possibilidade para formas da organização do trabalho. O condicionamento de possibilidades se expressa na variação das formas de organização do trabalho sob uma mesma base, sabendo que determinar as possibilidades também é limitá-las. A organização do trabalho apresenta heterogeneidade e autonomia relativas frente à sua base técnica, o que também se expressa como potência das decisões gerenciais, isto é, são plenamente possíveis, até certo limite, modificações na organização do trabalho sem que sejam provocadas modificações na base técnica, e vice-versa. Assim, base técnica e organização do trabalho são diferentes e formam uma unidade de reciprocidades. As modificações na base técnica e na organização do trabalho, e, eventualmente, na unidade como um todo, são problemas de investigação empírico-concreta. Entretanto, é possível traçar as tendências dominantes, considerando que a base técnica é o fator preponderante na relação com a organização do trabalho, isto é, aquele que engendra as condições de possibilidade, que existe como pressuposto objetivo. Por um lado, como a base técnica forma objetivamente as possibilidades que são impressas na organização do trabalho, uma modificação incremental e radical na primeira deve ser sentida na segunda, em menor ou maior grau. Sendo radical, torna a segunda sem correspondência, senão impossível. Por outro lado, mudanças na organização do trabalho em graus variados afetam também a base técnica por estrangular as possibilidades inscritas na objetividade da segunda, cujos limites só podem ser superados com ruptura do princípio que fundamenta a própria base técnica.

A essa teoria corresponde uma classificação: (1) manufatura, (1A) manufatura moderna e (2) grande indústria como formas mais ou menos específicas da unidade entre base técnica e organização do trabalho. Teríamos também uma (2A) grande indústria moderna, mas extrapola as questões implicadas no período histórico da pesquisa (cf. Paço Cunha, 2019).

(1) A manufatura é, assim, uma unidade particular entre base técnica e organização do trabalho. O princípio fundamental dela é a divisão do trabalho, o trabalhador e seus instrumentos. Sua base técnica, portanto, é rudimentar. Em termos empíricos, considere o estágio de desenvolvimento da montagem de automóveis no início do século XX um exemplar de manufatura. A linha de montagem com instrumentos aperfeiçoados, entretanto, não altera o princípio da base técnica que se mantém como a divisão do trabalho, o trabalhador e seus instrumentos. O mais alto grau de mecanização foi possível historicamente sobre uma base manufatureira. Para constatar isso, basta averiguar o desenvolvimento do toyotismo até o limite de sua base técnica.

(2) A grande indústria, por outro lado, instaura-se sobre outro princípio articulador entre base técnica e organização do trabalho, por isso se fala em mudança radical. Trata-se especificamente da revolução dos meios de produção e do estabelecimento de um sistema de máquinas ao qual se acopla uma organização do trabalho. Não que não haja agora uma divisão do trabalho. Ao contrário, ela repousa sobre uma organização sistemática do maquinismo automatizado, transformando a divisão do trabalho e o trabalho mesmo em elementos secundários frente à maquinaria. Mais uma vez em termos empíricos, o sistema de máquinas se desenvolveu tardiamente na montagem de automóveis, que permaneceu muito dependente das modificações na organização do trabalho (fordismo, toyotismo) durante a maior parte do século XX. Outros setores, como o químico e o têxtil, foram, em comparação, precocemente automatizados no século XIX e dispensaram formas de organização do trabalho correspondentes à base da manufatura, como o fordismo (Moraes, 1991, 2003). A mesma conclusão se tem com a fabricação estadunidense de latas, já totalmente automatizada no início do século XX (Pearson, 2016).

(1A) Há um estágio intermediário de transição entre os leitos da manufatura e da automação (Moraes, 2003). A manufatura moderna expressa o processo gradativo de mecanização tendo o princípio da manufatura por base, com adoção de esteiras e outros maquinismos seletivamente inseridos em certas etapas de uma produção, sem com isso ocorrer alteração do padrão geral daquela produção, isto é, sem estabelecer um sistema de máquinas completo. 0 fordismo e o toyotismo são exemplos empiricamente emblemáticos da organização do trabalho sobre uma base técnica progressivamente mecanizada e que estrangulam, assim, o princípio manufatureiro que forma sua base. 0 desenvolvimento da organização manufatureira do trabalho que se baseia numa base técnica cada vez mais mecanizada leva o princípio da manufatura ao paroxismo, cuja superação só foi possível historicamente pela instauração de um predominante sistema de máquinas.

Nesses termos, assume-se que a montagem de autoveículos se constituiu como manufatura e, depois, como manufatura moderna, espelhando um processo progressivo de mecanização ao longo do século XX, antes de seu salto ao "leito da automação", a partir dos anos de 1970. Foi possível historicamente, portanto, a coexistência entre setores muito avançados tecnologicamente, como aqueles de fluxo contínuo nos quais já se empregavam processos automatizados, e setores 
aparentemente sofisticados cujo fundamento, porém, refletia princípios arcaicos, a exemplo da montagem automobilística (Fortes, 2019), na qual se destacaram o fordismo e o toyotismo no século XX.

A esse respeito, pode-se especificar a intransitividade entre fordismo/toyotismo e uma base técnica da grande indústria tipicamente baseada no sistema de máquinas, uma vez que os primeiros se lastreiam no trabalho vivo.

Este fato crucial [de se lastrearem no trabalho vivo] fornece ao fordismo/ohnoísmo sua diferença específica relativamente à produção em massa lastreada na maquinaria, caso típico das indústrias têxtil e de processo contínuo. Ora, a automação de base microeletrônica terá como consequência permitir às indústrias de cunho fordista ou ohnoísta passar a alicerçar a produção em massa (necessariamente flexível) na maquinaria, e não mais no trabalho vivo. Isto significará, simplesmente, o fim histórico do fordismo, e de sua "reinvenção", o ohnoísmo, e a emergência de um conceito unificado de produção industrial, que se constituirá, em todos os seus segmentos, numa "aplicação tecnológica da ciência" (Moraes, 2003, p. 109).

Com a transição para o sistema de máquinas, fordismo e toyotismo perderam sua base real. Isso fica mais destacado quando se reconhece que o lastro do toyotismo no trabalho vivo está marcado desde sua constituição, pois "Toyota escolhe enfrentar este brutal aumento da demanda sem aumentar seu pessoal. Assim sendo, a única via aberta era a de uma racionalização do trabalho apoiada no maior rendimento possível do trabalho vivo" (Coriat, 1994, p. 55, grifo nosso). Mesmo o aspecto mais objetivo, por assim dizer, do toyotismo, na figura do Kan-ban ou just in time, está associado ao capital circulante - estoques, sobretudo -, e não necessariamente à aplicação tecnológica em maquinaria produtiva. Objetivando uma produção enxuta, trata-se essencialmente de um "modo eficiente (desde que cercado das condições industriais e culturais pertinentes) de organizar a produção (social)" (Tauile, 1988, p. 71). Não por acaso há tanto destaque ao papel dos processos de convencimento e adesão da força de trabalho como condição de funcionalidade dessa organização do trabalho sobre uma base manufatureira.

Assim, por mais importantes que sejam como inovações organizacionais, fordismo e toyotismo, na indústria de autoveículos, não configuraram por si mesmos saltos qualitativos no princípio operativo em direção à grande indústria, embora tenham ajudado a preparar o terreno ao estrangular cada vez mais o princípio da manufatura ao longo do século XX, dadas as reciprocidades existentes entre base técnica e organização do trabalho. Por fim, o salto desse setor, e de setores de peso nas economias centrais, para o "leito da automação" pode ser considerado uma "grande convergência" de relevância explicativa para os efeitos observados a partir da década de 1970 (Paço Cunha, 2019).

Essa transição na montagem de carros, particularmente no Brasil, é o objeto primário que demanda apreensão, cabendo especificar, dadas as lacunas apresentadas, o período de ocorrência da inflexão entre manufatura moderna e grande indústria nesse importante setor da economia brasileira.

\section{ASPECTOS METODOLÓGICOS}

A investigação empírica do artigo está pautada em metodologia qualitativa, com o uso de pesquisa documental, e quantitativa, utilizando-se estatística básica (Oliveira, 2001). A abordagem geral se ancora no materialismo presente na crítica da economia política, para o qual a natureza do próprio objeto - no caso, a inflexão - impõe os meios adequados de sua investigação (Chasin, 2009).

Na impossibilidade de observação direta da inflexão e no interesse de superar os limites dos estudos de caso acumulados na literatura sobre o setor de autoveículos no Brasil, a análise deve se pautar no comportamento de variáveis e de suas relações como medidas de aproximação do problema em tela. Assim, a inflexão própria da base técnica está inacessível a uma abordagem direta, mesmo ao nível da empresa. Entretanto, a abordagem indireta, considerando o agregado do setor em tela, é muito comum na pesquisa científica de "natureza fática" (Bunge, 2001, pp. 12-19), isto é, aquela que necessita de observação e de ajuste das hipóteses aos fatos, exigindo, para o caso, a observação dos efeitos dados a posteriori e provocados pela inflexão num momento anterior. 
Esse tipo de modificação radical do princípio da base técnica, parafraseando Marx (2010, p. 263), "pode ser objeto de rigorosa verificação da ciência natural". Para o caso, é passível de observação, coleção de evidências e medição. 0 desafio passa a ser capturar indiretamente e registrar a mudança do princípio da manufatura moderna para o da grande indústria no setor de autoveículos brasileiro, isto é, a aproximação do instante empírico de um processo dinâmico mais longo.

O processo de mudança técnica não é apenas dinâmico, mas também total, envolvendo diferentes forças. Entretanto, o registro mais cientificamente rigoroso das perturbações provocadas pela mudança daquele princípio exige a extração da base técnica de seus múltiplos nexos por meio de procedimento abstrativo provisório. Deve-se assumir a dificuldade de analisar a referida mudança em meio a uma multiplicidade de relações. Tais relações devem ser sempre pressupostas e restabelecidas numa análise posterior de conjunto, demandando trabalhos dedicados ao assunto. $\mathrm{O}$ avanço sobre outros nexos depende, porém, da análise nos detalhes.

Uma vez isolada a base técnica, tem-se que a modificação para a grande indústria apresenta efeitos econômicos conhecidos que são metodologicamente significativos (Marquetti \& Porsse, 2014; Marx, 2013). Dito de outro modo, a transição não diretamente observável no princípio deve produzir a posteriori perturbações observáveis em determinados fatores econômicos. Não se deve ignorar que tais perturbações observáveis possam derivar de outras forças, como aquelas decorrentes da expansão dos mercados. Por isso, é decisiva a delimitação dos aspectos associados à produção. Marquetti e Porsse (2014) destacaram, por exemplo, o crescimento da produtividade do trabalho, a queda da produtividade do capital, o aumento da intensidade do capital, entre outros. Nessa direção, embora as modificações na organização do trabalho possam provocar efeitos igualmente relevantes, a mudança técnica na transição entre manufatura moderna e grande indústria produz, comparativamente, efeitos mais profundos na potência produtiva como reflexo da aplicação científica e do avanço tecnológico - isto é, aplicação do capital -, bem como, igualmente, nas qualidades da força de trabalho. A diferença marcante, contudo, é que a inflexão técnica repercute em mais fatores econômicos associados ao capital investido em meios de produção do que a organização do trabalho poderia engendrar. Desse modo, é decisiva a atenção aos efeitos que refletem a ampliação da potência produtiva tecnologicamente orientada.

Para realizar a análise, delimitou-se, por um lado, o setor de autoveículos no Brasil, considerado pela Anfavea como montagem de carros, caminhões e ônibus. Essa primeira delimitação serviu ao levantamento documental para uma aproximação qualitativa do problema empírico sob investigação, incluindo livros, jornais e relatórios técnicos que auxiliaram na evidenciação da introdução da robótica como índice da mudança técnica em curso no período analisado. Por outro lado, delimitaram-se os fatores que permitiriam observar os efeitos econômicos decorrentes de uma transição da manufatura moderna para a grande indústria no setor e procuraram-se dados que pudessem expressar seus comportamentos. A observação desses fatores possibilita a verificação da hipótese de trabalho, que, para o presente caso, tem caráter de probabilidade (Bunge, 2001), isto é, trabalha-se de modo restrito a uma delimitação de período provável da inflexão ao nível do setor, e não um momento singular no tempo ao nível da firma.

Calculou-se a produtividade do trabalho, medida pelas unidades produzidas mensalmente em razão do número de trabalhadores ocupados mensalmente, e o comportamento da produção total e venda de unidades - esta compreendendo licenciamentos nacionais e exportações -, com base nos dados da Anfavea. Essa medida das vendas permitiu excluir a hipótese de que as perturbações observadas fossem decorrência da expansão do mercado, como será evidenciado. Adicionalmente, com base na Pesquisa Industrial Anual do IBGE (PIA), disponível no Sistema IBGE de Recuperação Automática (Sidra), foram extraídos o valor da produção (VP) medido em preços dos produtos e o capital constante (CC) como soma entre capital fixo e circulante, considerando o capital fixo custos de depreciação - que expressam quanto de capital fixo foi gasto durante o ano -, aluguéis e arrendamentos (leasing) de equipamentos, somados ao saldo de aquisições de ativo fixo (aquisições + melhorias - baixas), e considerando o capital circulante como custos de matéria-prima, consumo de peças e acessórios, serviços prestados de manutenção e demais custos operacionais. Da mesma base de dados foram extraídos o número de trabalhadores ocupados (T), a massa salarial anual (S) - o somatório dos salários pagos - e o número de empresas (E).

Todos os dados medidos em preço foram deflacionados a preços de 2017 pelo índice IGP-DI (FGV).

A análise dos indicadores com base nas variáveis indicadas acima cobriu o período de 1996 a 2017 por duas razões fundamentais. Em primeiro lugar, houve modificação da metodologia de levantamento e exposição dos dados da Pesquisa Industrial Anual do IBGE. A partir de 1996, a pesquisa passou a ser anual e apresentar as variáveis utilizadas no cálculo dos indicadores no nível de desagregação necessário - fabricação de automóveis, camionetas, caminhões e ônibus (IBGE, 1996). Depois, realizou-se 
análise, apresentada no começo da próxima seção, sobre indicadores de faturamento, produtividade do trabalho, introdução da robótica e níveis de investimentos, com base nos dados da Anfavea, em bibliografia especializada e em jornais da época. Tal análise sugeriu que não houve, até 1996, a concreção da inflexão na base técnica presente na produção de autoveículos no Brasil.

Por conseguinte, foi possível considerar as seguintes medidas e o sentido de suas variações para a inflexão entre manufatura moderna e grande indústria no setor: (1) produtividade do capital (VP/CC), medida pela razão entre o valor - medido para todos os casos em preços - da produção (VP) e o capital constante (CC), em que variações negativas ou estagnadas sinalizam a ocorrência da inflexão; (2) a intensidade do capital (CC/T), aferida na relação entre capital constante (CC) e o número de trabalhadores ocupados (T), em que variações positivas são indicativas; (3) o salário médio anual (S/T), cuja variação negativa é indicativa; (4) o capital constante por empresa (CC/E), cuja variação positiva é indicativa; (5) o número de trabalhadores por empresa (T/E), em que a variação negativa é indicativa; (6) a composição orgânica (CC/S) como razão entre o capital constante (CC) e os salários totais (S), cuja variação positiva indica com mais vigor a inflexão; (7) produtividade do salário medida pela razão entre o valor produzido e a massa de salários (VP/S) que aprofunda a indicação pela variação positiva ao acompanhar aproximadamente a composição orgânica. Por fim, analisou-se (8) a modificação da composição das ocupações no setor ao longo do período, pois elas são diretamente influenciadas pela inflexão tecnológica. Com base nos dados da Rais, analisou-se a variação das ocupações com maior número de trabalhadores no setor nos anos de 1996, 2001, 2006, 2011 e 2016. Com a transição para a grande indústria, observar-se-iam a diminuição de ocupações especializadas na operação de certos equipamentos e o aparecimento de ocupações mais intensivas em tecnologias e maior presença de operações de manutenção.

Todas essas medidas foram úteis para analisar o período e delimitar a transição para a grande indústria no setor, levando em conta os efeitos observados. Como dito, foi necessário descartar a hipótese de que as perturbações observadas eram condicionadas primariamente pelo número das vendas. Isso aprofunda a justificativa de considerar as relações de variáveis mais associadas ao capital constante. Analisando as variáveis dessa maneira, tornou-se possível verificar com maior precisão a ocorrência da inflexão da base técnica, com o aumento mais destacado do capital constante como anterioridade à expansão de mercado.

\section{ANÁLISE DOS DADOS}

Tendo em vista o objetivo de delimitar empiricamente no tempo a inflexão do princípio na base técnica, isto é, a conversão da montagem de automóveis como manufatura moderna à grande indústria, está suposta a superação das lacunas deixadas pela literatura quanto à mudança técnica propriamente dita e a indicação mais precisa da temporalidade dessa mudança no setor de autoveículos brasileiro.

Apesar de tais lacunas e de o enfoque ter se deslocado para a organização do trabalho, há importantes evidências do processo de mudança tecnológica no setor de autoveículos brasileiro a partir dos anos de 1980. As pesquisas deram grande destaque aos efeitos da introdução da microeletrônica e da robótica naquela década. No entanto, o diagnóstico geral foi o de uma "introdução seletiva" em determinadas etapas da produção (Carvalho, 1987; Peliano et al., 1987; Schmitz \& Carvalho, 1988, 1989; Vieira, 1985), o que não alterava radicalmente o padrão de manufatura moderna então estabelecido. Não por acaso, constatou-se, já em 1990, que o fordismo seguia vivo no Brasil (Carvalho \& Schmitz, 1990). Essa última constatação, contrariamente às intenções dos pesquisadores, decorre do fato de que a base técnica persistia como manufatura moderna, ainda que com grau de mecanização cada vez mais aguçado. Não obstante, alguns dados são indicativos de modificações tecnológicas que prepararam o terreno para as alterações mais fundamentais.

Se considerada a variável "faturamento líquido" com base nos dados da Associação Nacional dos Fabricantes de Veículos Automotores (Anfavea, 2018), vê-se que, ao fim da década de 1980, registraram-se 14,9 bilhões de dólares, e, para o fim de 1990, 12,2 bilhões, números pouco díspares. O mesmo ocorreu com a produtividade, considerando veículos produzidos por trabalhador ao ano, que alcançou 0,68 em dezembro de 1983 e 0,66 no mesmo mês de 1992. Entretanto, a década de 1990 representou, consistentemente, uma mudança marcante quanto à aceleração da introdução da robótica nos processos centrais de produção de veículos no Brasil. Alguns aspectos são destacáveis diante da crise de então. Como mostrou Luedemann (2003), entre esses fatores se observou a participação central do Estado, como a facilitação de importação de maquinaria e 
incentivos fiscais e a decisão das principais montadoras em produzir modelos internacionalmente padronizados em linhas de montagem mais automatizadas.

O resultado de conjunto se manifestou em modificações importantes nas principais plantas e na instalação de várias plantas novas de multinacionais entrantes, instaladas com as linhas de montagem com alto grau de automatização e aplicação da robótica. Exemplos desses processos de difusão da robótica, excetuando as entrantes, podem ser acompanhados no Quadro 1.

\section{Quadro 1}

Introdução de robôs nas plantas de autoveículos no Brasil (1990-2000)

\begin{tabular}{|c|l|}
\hline \multicolumn{1}{|c|}{ Planta } & \multicolumn{1}{c|}{ Descrição da modificação } \\
\hline General Motors & $\begin{array}{l}\text { Em 1996, introdução de } 377 \text { robôs em } 2 \text { linhas de produção (Luedemann, 2003). Em 2000, foi ainda } \\
\text { aberta uma nova planta com 120 robôs (Carvalho, 2003). }\end{array}$ \\
\hline Volkswagen & $\begin{array}{l}\text { Em 1997, eram 167 robôs (Carvalho, 2003). No início dos anos 2000, passaram a } 400 \text { (Jornal do } \\
\text { Commercio, 2001). }\end{array}$ \\
\hline Ford & Um total de 230 robôs instalados na fábrica de Camaçari em 2001 (Firmino, 2003). \\
\hline Fiat & $\begin{array}{l}\text { Instalação de 38 robôs, em 1996, para a montagem do Palio. Já nesse período, outras linhas de } \\
\text { montagem ainda não contavam com robôs (Jornal do Brasil, 1996). }\end{array}$ \\
\hline Volvo & Planta instalada com 8 robôs (Ribeiro, 1997). \\
\hline Scania & $\begin{array}{l}\text { Em 1994, 15 robôs distribuídos nas linhas de motores, eixos, cabines, chassis e montagem final } \\
\text { (Luedemann, 2003). }\end{array}$ \\
\hline
\end{tabular}

Nota: sistematização de informações encontradas em teses e jornais de circulação nacional que cobriram o processo de introdução da robótica disponíveis no acervo da Hemeroteca Digital da Biblioteca Nacional.

Fonte: Elaborado pelos autores.

Essa mudança de conjunto é reflexo do surto de investimentos que consistiram, em média, em 1,6 bilhão de dólares entre 1994 e 2001 (Anfavea, 2010). Uma breve análise dos investimentos entre 1990 e 2012 mostra que o período de 1995 a 2001 representa uma fase de altíssimas inversões de capitais. No entanto, o setor de autoveículos ainda termina a década de 1990 em padrão semelhante à anterior, incorporando tecnologias com base microeletrônica de maneira progressiva, em que a expansão indicada da robótica é o índice das modificações em curso.

Os efeitos desses investimentos e, portanto, das modificações técnicas em andamento passam a ser observados indiretamente na década seguinte. Uma evidência disso é o número de veículos produzidos por trabalhador: 0,68 em dezembro de 1983, 0,66 no mesmo mês de 1992 e 1,86 em 2003 (Anfavea, 2020). O Gráfico 1 mostra, de forma mais abrangente, esse desenvolvimento da produtividade do trabalho, com destaque para o impulso ocorrido nos anos posteriores ao ano 2000 como efeito desses investimentos. 
Gráfico 1

Produtividade do trabalho no setor de autoveículos no Brasil (1996-2017)

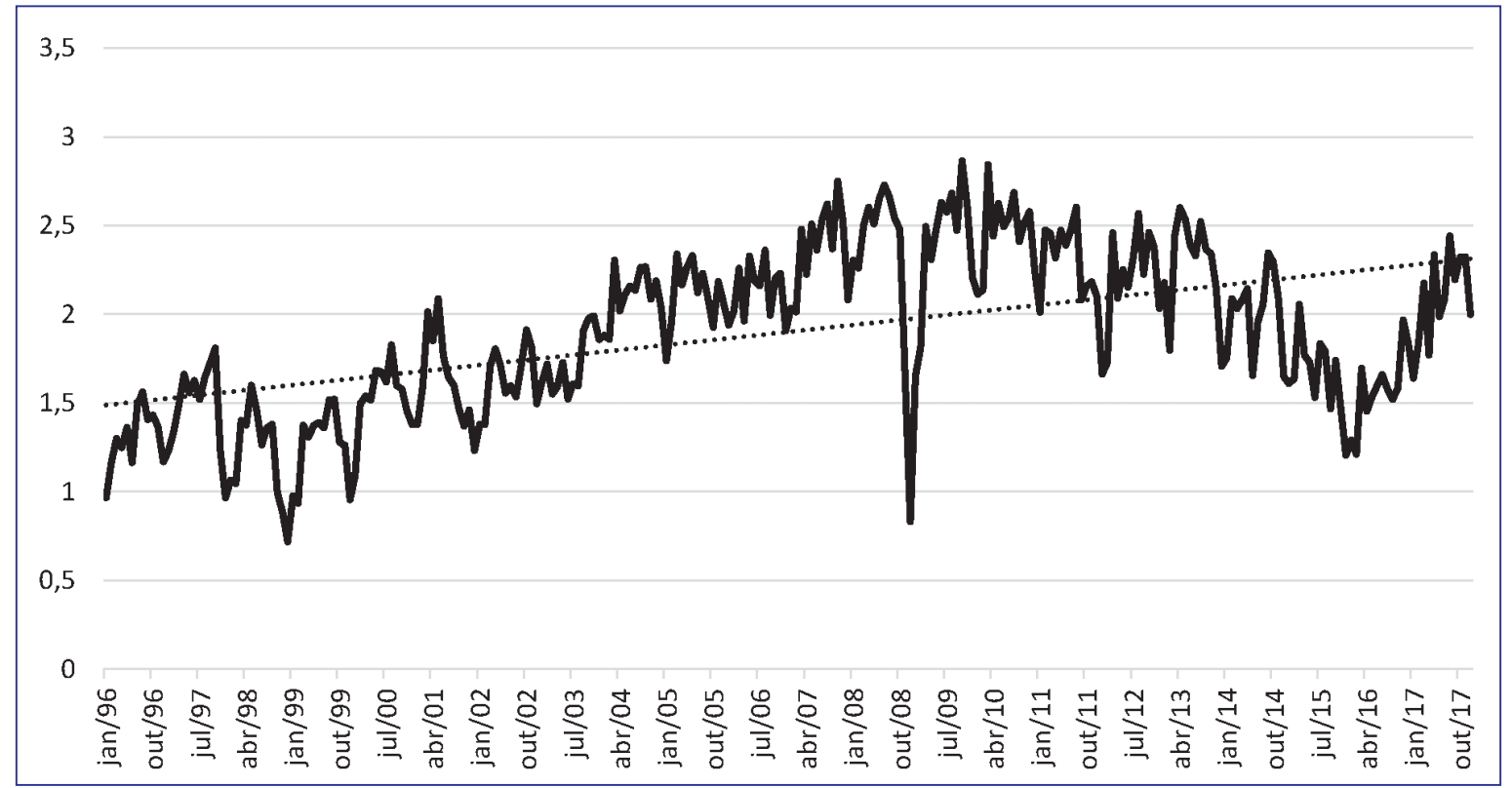

Nota: Produtividade do trabalho medida pelo número de autoveículos produzidos mensalmente (carros, caminhões e ônibus) dividido pelo número de trabalhadores ocupados mensalmente.

Fonte: Anfavea (2020a, 2020b).

É possível observar que os níveis de produtividade depois dos anos 2000 não decaem aos níveis da década de 1990 nem com as retrações de mercado após 2013, como ficam sugeridas pelo Gráfico 2. A tendência de expansão da produção e das vendas entre 1999 e 2013 (Gráfico 2), bem como o crescimento da produtividade do trabalho até 2010 (Gráfico 1), sinaliza a possibilidade de ocorrência da inflexão técnica a partir do ano 2000, pelo menos.

\section{Gráfico 2}

Produção e vendas de veículos no Brasil (1996-2017)

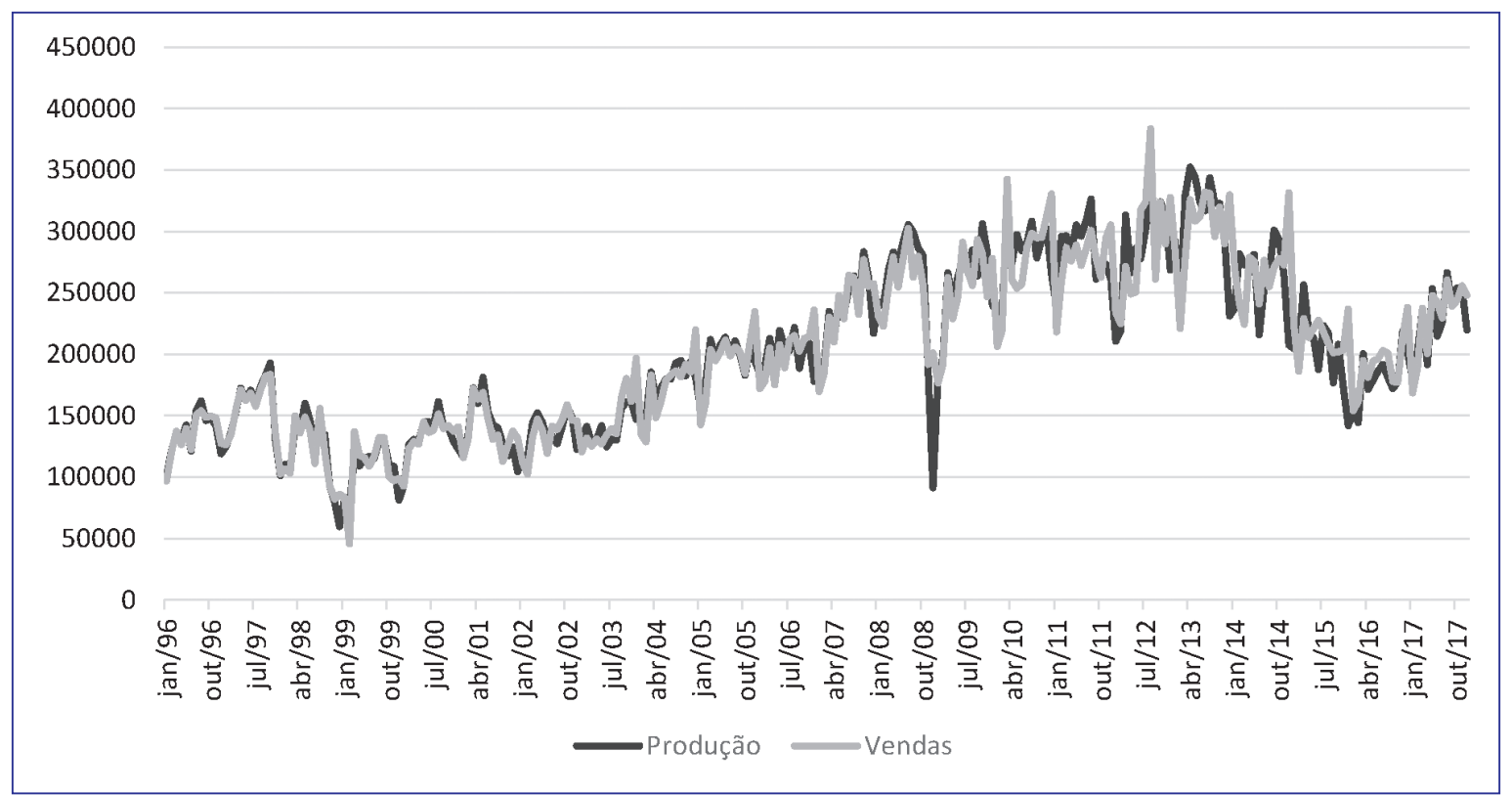

Nota: Quantidades mensais de produção e vendas (licenciamentos nacionais e exportações) de autoveículos.

Fonte: Anfavea (2020a). 
Indicadores de produção por trabalhador, produção total e vendas, todavia, são muito afetados por variações de mercado em decorrência das oscilações dos ciclos econômicos. Disso resulta a necessidade de análise mais apurada que permita verificar se as perturbações observadas decorrem da mudança do princípio técnico, e não das oscilações de mercado. Assim, cabe avaliar detidamente a variação dos aspectos mais centrais ao longo do período em estudo. Essa variação pode ser acompanhada na Tabela 1.

Tabela 1

Medidas econômicas calculadas para o setor de autoveículos brasileiro (1996-2017)

\begin{tabular}{c|c|c|c|c|c}
\hline Ano & $\mathrm{CC} / \mathrm{T}$ & $\mathrm{VP} / \mathrm{CC}$ & $\mathrm{S} / \mathrm{T}$ & $\mathrm{CC} / \mathrm{E}$ & $\mathrm{T} / \mathrm{E}$ \\
\hline 1999 & 130,6 & 74,3 & 107,9 & 97,1 & 74,3 \\
\hline 2003 & 164,3 & 77,4 & 95,3 & 78,3 & 47,7 \\
\hline 2007 & 161,5 & 92,5 & 91,3 & 123,5 & 76,5 \\
\hline 2011 & 149,2 & 99,7 & 100 & 138,2 & 92,6 \\
\hline 2014 & 139,3 & 91 & 100,1 & 116,7 & 83,8 \\
\hline 2017 & 140,5 & 84 & 93,4 & 108,4 & 77,2 \\
\hline
\end{tabular}

Nota: (CC/T) Intensidade do Capital, (VP/CC) Produtividade do capital, (S/T) Salário médio, (CC/E) Capital constante por empresa, (T/E) Trabalhador por empresa. Ano de 1996=100. Dados deflacionados a preços de 2017 pelo IGP-DI (FGV).

Fonte: Dados brutos do IBGE (2020).

A Tabela 1 compreende as variações percentuais das variáveis em diferentes anos, tendo 1996 por ano-base. É interessante destacar que, para todo o período considerado, há variação positiva da proporção de capital investido por trabalhador (CC/T) ao mesmo tempo que se reduz a relação entre produção e capital (VP/CC) e se observa certa estagnação do salário médio (S). Isso sugere que o investimento em capital foi acompanhado de modo desproporcional pela força de trabalho e pelos salários, sinalizando intensificação do capital constante. Trata-se de um efeito característico da inflexão para a grande indústria. Com base no período entre 1996 e 2003, aparece um decréscimo do capital por empresa (CC/E) que se explica pela expansão do número de montadoras, que saltou de 5 em 1996 para 13 em 2003 (Frainer, 2010, p. 79). Segue-se também uma queda considerável no número de trabalhadores por empresa (T/E) até 2003 e uma retomada posterior, que não alcança o nível de 1996 como ano-base. Isso encontra ressonância com os achados de Frainer (2010), para quem a expansão dos investimentos foi muito maior do que a dos empregos entre 2000 e 2004, o que se explica parcialmente em razão dos “investimentos intensivos em capital e, portanto, poupadores de mão de obra" (Frainer, 2010, p. 97). Isso reforça a hipótese de ocorrência da inflexão da base técnica no período entre 2000 e 2004.

É possível adicionar à análise o comportamento da composição orgânica (CC/S). Como sugerido na seção metodológica, quanto maior é essa composição, mais sinalizada fica a inflexão por retratar um crescimento mais acelerado dos investimentos potenciais em maquinaria. Na mesma direção está a relação entre o valor da produção (VP), medido em preços dos produtos, e os salários (S), em que quanto maior a taxa resultante (VP/S), maior a contribuição do quantum de rendimentos do trabalho para os preços relativos ou maior é a produtividade do salário. No Gráfico 3, a tendência de crescimento fica evidenciada entre 1999 e 2008 para as duas medidas. Tem-se um reforço da hipótese sob verificação, sobretudo quando se compara com o comportamento da curva do mesmo indicador para o restante da indústria nacional. A modificação da tendência se explica pelos fatores de mercado com a recessão iniciada com a crise dos subprime de 2008. 


\section{Gráfico 3}

\section{Composição orgânica e produtividade do salário no setor de autoveículos} no Brasil e no conjunto da economia brasileira (1996-2017)

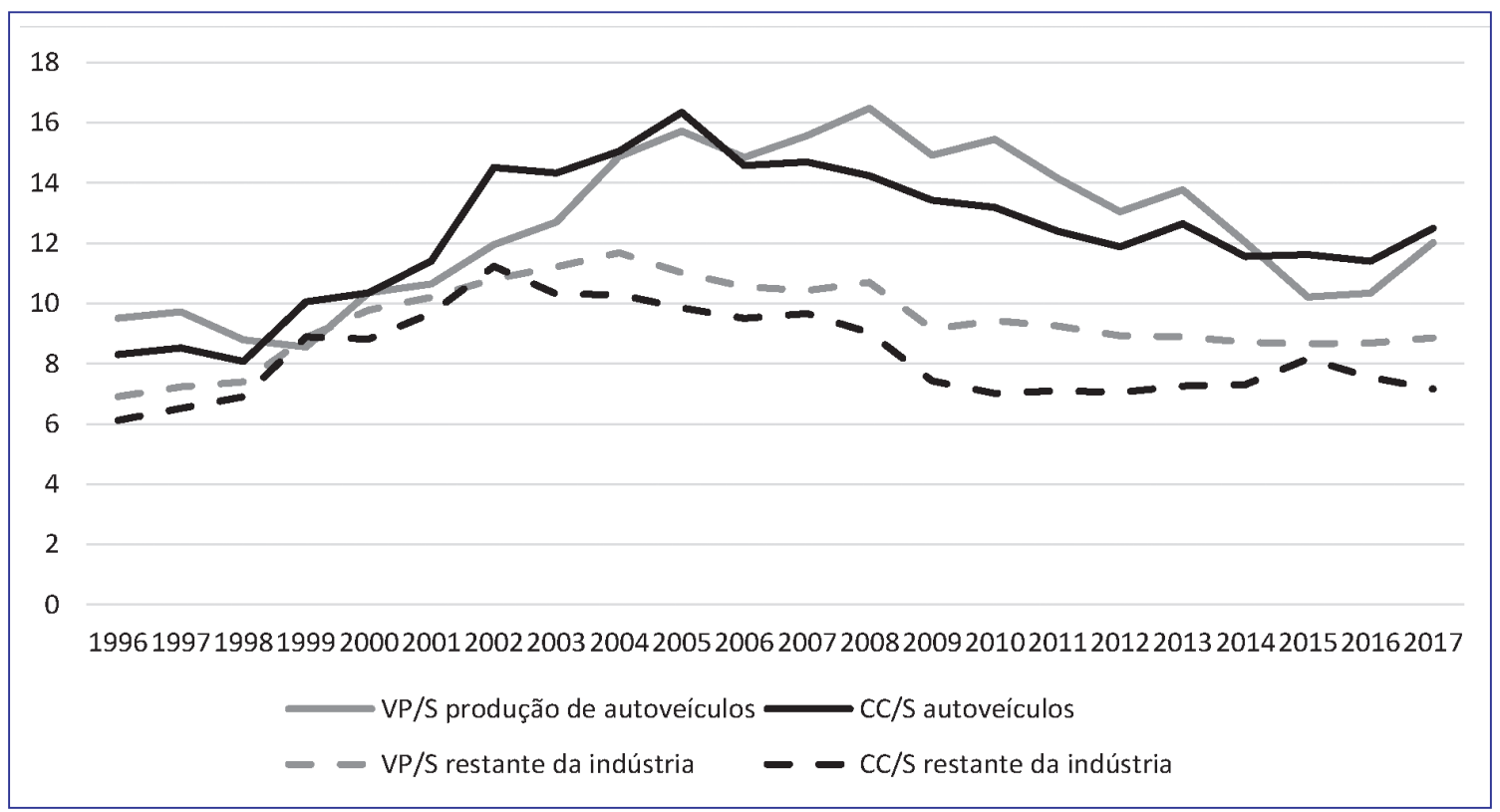

Nota: Composição orgânica (CC/S) medida pela soma de capital constante dividido pela massa salarial.

Produtividade do salário (VP/S) medida pela razão entre o valor da produção em preços e a massa de salários.

O restante da economia compreende os demais setores da indústria extrativa e de transformação.

Dados deflacionados a preços de 2017 pelo IGP-DI (FGV).

Fonte: IBGE (2020).

É nítido que a composição orgânica ( $\mathrm{CC} / \mathrm{S}$ ) no setor de autoveículos, além de atingir um patamar superior ao do restante do conjunto da economia brasileira, sustenta o crescimento e o patamar atingido ao longo dos anos 2000, mesmo após a crise de 2008. No restante da indústria, percebe-se um movimento mais errante e um crescimento com pouca sustentação a partir do início dos anos 2000. O mesmo movimento contrastante ocorre com a relação entre valor produzido e salários (VP/S). Essa relação, a propósito, atinge o ponto mais alto depois do auge da composição orgânica, mostrando-se um efeito daqueles investimentos intensivos em capital. É preciso destacar que, a partir de 2001, apesar das decaídas, os indicadores não retrocedem aos níveis dos anos anteriores, mesmo para aqueles de recessão mais aguda após 2014. Ou seja, nem a desaceleração do mercado faz com que $\mathrm{CC} / \mathrm{S}$ ou VP/S regridam ao momento de transição para a grande indústria que se apresenta cada vez mais delimitada para o período entre 2000 e 2004.

A decomposição, em particular da composição orgânica (CC/S), em seus termos relacionados, permite observar o fator mais contributivo ao comportamento observado. Há, em geral, resultados condicionados pelas diferenças de tendências e velocidade. Uma mesma taxa de composição poderia ser obtida com estagnação do capital constante e queda dos salários, por exemplo, ou crescimento com velocidade desproporcional por parte do numerador da relação. Entretanto, os dados sugerem outra conclusão. $\mathrm{O}$ Gráfico 4 permite a constatação sobre a diferença entre as tendências dos 2 fatores. 


\section{Gráfico 4}

Capital constante e massa salarial no setor de autoveículos no Brasil (1996-2017)

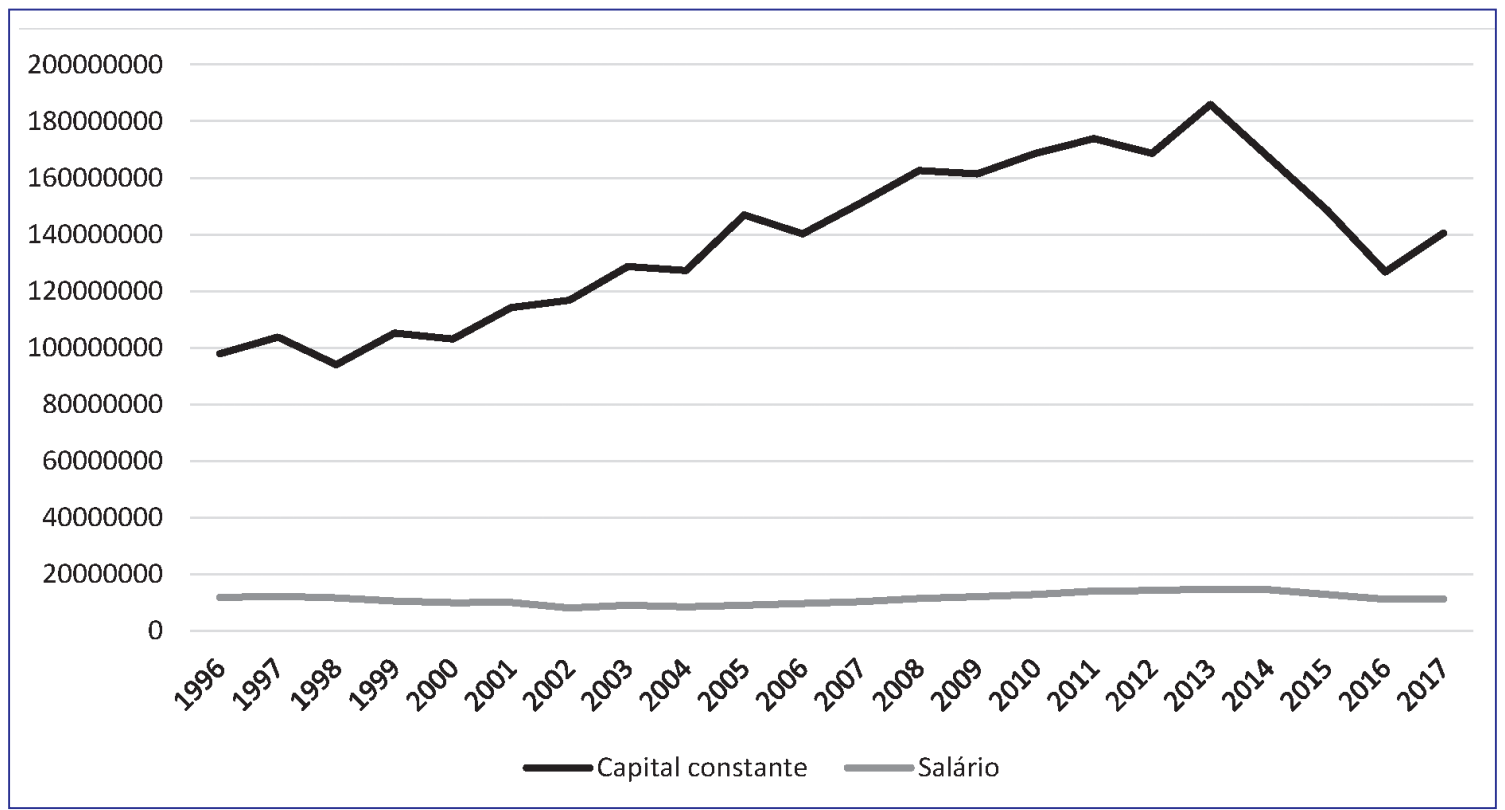

Nota: Desdobramento anual do investimento em Capital Constante (CC) e em salários (S) na produção de autoveículos no Brasil. Dados deflacionados a preços de 2017 pelo IGP-DI (FGV).

Fonte: IBGE (2020).

O crescimento da composição orgânica foi sustentado pelo aumento do capital constante, e não pelo decréscimo nos salários ou por velocidades desproporcionais de crescimento dos fatores. Esse crescimento é sintomático do desenvolvimento da grande indústria como padrão distinto da década anterior, e é possível delimitar a "grande convergência", isto é, o salto para o leito da automação, para esse período. Essa conclusão se torna mais evidente se somada aos achados anteriores de Marquetti e Porsse (2014), para quem se constituiu um novo padrão técnico no Brasil entre 1991 e 2008, com a desvantagem de estabelecer um intervalo mais amplo do que as evidências colecionadas sugerem.

Por fim, mudanças importantes também ocorreram na composição da força de trabalho por decorrência de uma anterior inflexão da base técnica. A Tabela 2 apresenta o desenvolvimento da representatividade dessas ocupações com a modificação da proporção de cada uma em relação ao total de trabalhadores. 
Tabela 2

Variação da composição proporcional da força de trabalho no setor de autoveículos no Brasil (2001-2016)

\begin{tabular}{|c|c|c|c|c|}
\hline Ocupações & $2001(\%)$ & $2006(\%)$ & $2011(\%)$ & $2016(\%)$ \\
\hline $\begin{array}{l}\text { Ajustadores mecânicos, montadores e mecânicos de } \\
\text { máquinas, veículos e instrumentos de precisão }\end{array}$ & 107,37 & 126,61 & 138,27 & 118,46 \\
\hline Trabalhadores da usinagem de metais & 92,55 & 62,40 & 47,57 & 38,48 \\
\hline $\begin{array}{l}\text { Encanadores, soldadores, chapeadores, caldeireiros e } \\
\text { montadores de estruturas metálicas }\end{array}$ & 105,01 & 85,24 & 82,33 & 55,61 \\
\hline $\begin{array}{l}\text { Técnicos, desenhistas técnicos e trabalhadores } \\
\text { assemelhados }\end{array}$ & 120,06 & 79,7 & 60,7 & 75,03 \\
\hline Pintores & 108,79 & 99,65 & 106,75 & 78,50 \\
\hline Eletricistas, eletrônicos e trabalhadores assemelhados & 44,53 & 35,33 & 44,06 & 58,16 \\
\hline $\begin{array}{l}\text { Mestres, contramestres, supervisores de produção e } \\
\text { manutenção industrial e trabalhadores assemelhados }\end{array}$ & 82,04 & 67,64 & 93,24 & 115,30 \\
\hline $\begin{array}{l}\text { Trabalhadores da movimentação e manipulação de } \\
\text { mercadorias e materiais }\end{array}$ & 83,45 & 70,51 & 77,08 & 97,82 \\
\hline Engenheiros, arquitetos e trabalhadores assemelhados & 124,28 & 168,15 & 183,16 & 207,12 \\
\hline $\begin{array}{l}\text { Economistas, administradores, contadores, gerentes e } \\
\text { trabalhadores assemelhados }\end{array}$ & 135,76 & 184,47 & 189,51 & 246,63 \\
\hline Alimentador de linha de produção & - & 100,00 & 150,68 & 442,05 \\
\hline Inspetor de qualidade & - & 100,00 & 96,39 & 96,09 \\
\hline
\end{tabular}

Nota: Variação da proporção das profissões em relação ao quantitativo total de força de trabalho da montagem de autoveículos considerando 1996 como ano-base (1996=100). A partir de 2002, o método de categorização das profissões é modificado pelo IBGE. Assim, em 2006, são verificadas novas profissões com um alto quantitativo de trabalhadores, como alimentador de linha de produção e inspetor de qualidade.

Fonte: Dados brutos do Ministério do Trabalho e Emprego (MTE, 2020).

Em relação à composição qualitativa, é possível dizer que houve, por um lado, o aumento importante do número de engenheiros, gestores e trabalhadores cuja ocupação é alimentar a linha de produção, montar veículos e atuar na manutenção de máquinas. Por outro lado, esse crescimento que se inicia em 2001 e se acentua ao longo do tempo foi acompanhado pelo decréscimo relativo das ocupações mais especializadas, como técnicos, pintores, eletricistas e soldadores. Embora algumas modificações centrais e permanentes já tivessem aparecido em 2001 - como o aumento da importância dos engenheiros, crescimento do número de trabalhadores localizados na montagem e diminuição de eletricistas -, as modificações se sedimentaram ao longo da década de 2000, com a progressiva queda de desenhistas e trabalhadores da usinagem e o aparecimento de outras ocupações ligadas ao controle de qualidade e à própria atuação na linha de montagem. É preciso ressaltar, contudo, que a mudança tecnológica não representou a eliminação das ocupações mais especializadas, mas reduziu seu peso no quantitativo total, modificando qualitativamente o conjunto da força de trabalho. Em suma, há uma progressiva modificação intensificada a partir de 2001, quando as ocupações mais especializadas passam a ceder espaço a outras mais ligadas à projeção do funcionamento das fábricas, ao seu funcionamento operacional propriamente (gestores e engenheiros), ao acompanhamento da linha de produção e à manutenção dos meios produtivos constituintes do processo.

Em termos conclusivos, o estudo sugere que a inflexão da manufatura moderna para a grande indústria no setor de autoveículos no Brasil provavelmente se concentrou entre os anos 2000 e 2004, considerando os fatores analisados e seus comportamentos para o período. Assim, considera-se que a hipótese de trabalho pôde ser confirmada. 


\section{CONSIDERAÇÕES FINAIS}

O objetivo do presente artigo foi delimitar empiricamente a inflexão do princípio na base técnica para o setor de autoveículos brasileiro, demarcando o período com maior probabilidade de ocorrência da transição entre manufatura moderna e grande indústria no setor.

Realizou-se a pesquisa com a hipótese de que essa transição ocorreu tardiamente no Brasil, não antes dos anos 2000. Para verificá-la, trabalhou-se com análise de determinados fatores observáveis no período entre 1996 e 2017 que fornecem evidências significativas da ocorrência da inflexão da base técnica.

Ao analisar tais fatores, foi possível confirmar a hipótese de trabalho e delimitar melhor o período de ocorrência. As evidências sugerem que a mudança da base técnica no setor teve lugar com maior probabilidade entre 2000 e 2004 . O período testemunha o momento que procede às inversões de capitais e que precede o comportamento observável das variáveis destacadas e que são indicativas, incluindo a modificação da composição da força de trabalho para o setor anos mais tarde.

Uma das principais limitações da pesquisa é seu nível de análise. Como ela operou ao nível do agregado econômico, a observação das perturbações provocadas pela mudança técnica acumulada é relativamente independente do grau de conversão da base técnica. Ao nível da firma, entretanto, fará grande diferença a consideração do estágio da inflexão, do grau em que a produção foi tomada pela maquinaria. Assim, é uma questão importante para a continuidade da pesquisa e do estudo de outros setores a resolução de como fixar a inflexão no plano de um processo de produção em termos de grau. Há também a limitação adicional referente ao período coberto pela pesquisa quanto aos indicadores (a partir de 1996) e a qualidade dos dados disponíveis. Como sugerido na Introdução, colheu-se hipótese a partir da literatura que sugeria não ter ocorrido alteração aguda na base técnica antes dos anos 2000. A extensão do período de análise pode ser uma tarefa importante a ser considerada, levando em conta que os dados disponíveis para o período anterior a 1996 não se apresentam desagregados para possibilitar as mesmas análises realizadas no presente artigo, conforme sublinhado na seção sobre os aspectos metodológicos. $O$ próprio caráter da pesquisa, que procurou estabelecer o período de maior probabilidade de inflexão para a grande indústria no setor, deixa aberta a vereda para investigações adicionais. Nessa direção, estudos comparados a setores igualmente manufatureiros, ou, ao contrário, que já se mostravam inteiramente vertidos para a grande indústria, podem ser contributivos para o aprofundamento da investigação realizada.

Por fim, há um direcionamento também interessante para a continuidade da pesquisa. A literatura mais robusta consagrou a sugestão de que o processo "seletivo" de introdução das novas tecnologias - em etapas escolhidas do processo de produção no setor foi um traço característico do Brasil, podendo ser estendido para outros países com semelhantes condições socioeconômicas, sobretudo entre os que apresentam baixos níveis salariais (cf. Carvalho, 1987). Há uma hipótese cuja verificação seria contributiva para o conjunto dos conhecimentos sobre o assunto: o processo seletivo de introdução de novas tecnologias que provocam a transição entre manufatura moderna e grande indústria é uma particularidade dos países de baixos níveis salariais? A problemática se torna mais interessante na medida em que há evidências na literatura de que a introdução de novas tecnologias na produção de autoveículos é seletiva mesmo em países de economias mais avançadas, diferenciando-se pela velocidade em que o grau de automação atinge elevado patamar (Koshiro, 1987). A mesma problemática se coloca para a investigação da transição entre grande indústria e grande indústria moderna, com o desenvolvimento de machine learning e outros expedientes no contexto da assim chamada 4ạ Revolução Industrial.

\section{AGRADECIMENTOS}

Agradecemos à Fundação de Amparo à Pesquisa do Estado de Minas Gerais (Fapemig), pelo apoio financeiro ao projeto que gerou o presente artigo, e à Coordenação de Aperfeiçoamento de Pessoal de Nível Superior (Capes), pela concessão de bolsa de doutoramento para um de seus autores. 


\section{REFERÊNCIAS}

Acemoglu, D., \& Restrepo, P. (2020). Robots and jobs: Evidence from US labor markets. Journal of Political Economy, 128(6), 2188-2244.

Associação Nacional de Fabricantes de Veículos Automotores. (2010). Anuário da Indústria Automobilística Brasileira. Recuperado de http:// www.virapagina.com.br/anfavea2010

Associação Nacional de Fabricantes de Veículos Automotores. (2018). Anuário da Indústria Automobilística Brasileira. Recuperado de http:// www.virapagina.com.br/anfavea2018

Associação Nacional de Fabricantes de Veículos Automotores. (2020a). Séries mensais, a partir de janeiro/1957, de autoveículos por segmento (automóveis, comerciais leves, caminhões, ônibus, total) de produção; licenciamento de nacionais, importados e total; exportações em unidades. Recuperado de http://www.anfavea. com.br/estatisticas

Associação Nacional de Fabricantes de Veículos Automotores. (2020b). Séries mensais, a partir de janeiro/1983, do número de empregos por setores (autoveículos; máquinas agrícolas e rodoviárias). Recuperado de http://www.anfavea.com.br/estatisticas

Bunge, M. (2001). La ciencia: su método y su filosofía (4a ed.). Buenos Aires, Argentina: Editorial Sudamericana.

Carvalho, E. G. (2003). Globalização e estratégias competitivas na indústria automobilística: uma abordagem a partir das principais montadoras instaladas no Brasil (Tese de Doutorado). Universidade Estadual de Campinas, Campinas, SP. Recuperado de http://repositorio.unicamp.br/bitstream/REPOSIP/286207/1/Carvalho_ EneasGoncalvesde_D.pdf

Carvalho, R. D. Q. (1987). Tecnologia e trabalho industrial: as implicações sociais da automação microelectrônica na indústria automobilística. Porto Alegre, RS: L \& Pm Editora.

Carvalho, R. de Q., \& Schmitz, H. (1990). O fordismo está vivo no Brasil. Novos estudos CEBRAP, 27, 148-156

Chasin, J. (2009). Marx - Estatuto ontológico e resolução metodológica. São Paulo, SP: Editorial Boitempo.

Coriat, B. (1994). Pensar pelo avesso: o modelo japonês de trabalho e organização. Rio de Janeiro, RJ: UFRJ.

Dosi, G., \& Orsenigo, L. (1988). Coordination and transformation: an overview of structures, behaviours and change in evolutionary environments. In G. Dosi, C. Freeman, R. Nelson, G. Silverberg, \& L. Soete (Eds.), Technical change and economic theory. Pisa, Italy: Sant'Anna School of Advanced Studies.

Dosi, G., Teece, D. J., \& Chytry, J. (2005). Understanding industrial and corporate change. Oxford, UK: Oxford University Press.

Faria, J. H. de. (1992). Tecnologia e processo de trabalho. Curitiba, PR: Editora UFPR.

Firmino, H. (2003, novembro 08). O outro lado do Ecosport (p. 16). Jornal do Brasil. Recuperado de http://memoria.bn.br/ DocReader/030015_12/91516

Fortes, R. (2019). Limites e equívocos do conceito de acumulação fordista: desenvolvimento das forças produtivas e perpetuação das formas de produção arcaicas. Verinotio - Revista on-line de Filosofia e Ciências Humanas, 24(2), 58-87.

Frainer, D. M. (2010). A estrutura e a dinâmica da indústria automobilística no Brasil (Tese de Doutorado). Universidade Federal do Rio Grande do Sul, Porto Alegre, RS. Recuperado de https://lume. ufrgs.br/handle/10183/30638

Instituto Brasileiro de Geografia e Estatística. (1996). Pesquisa Industrial-Empresa (Vol. 15). Rio de Janeiro, RJ: Autor. Recuperado de https://biblioteca.ibge.gov.br/visualizacao/periodicos/1719/ pia_1996_v15_empresa.pdf

Instituto Brasileiro de Geografia e Estatística. (2020). Pesquisa Industrial Anual 1996-2017. Sistema IBGE de Recuperação Automática. Recuperado de https://sidra.ibge.gov.br/pesquisa/pia-empresa/ tabelas/brasil/2017

Jornal do Brasil. (1996, abril 19). Controle informatizado (p. 25). Jornal do Brasil. Recuperado de http://memoria.bn.br/ DocReader/030015_11/166534

Jornal do Commercio. (2001, março 31). Volks vai demitir 2,5 mil no ABC (pp. 15-31) Jornal do Commercio. Recuperado de http://memoria.bn.br/DocReader/364568_19/18717

Kabat, M. (2005). Del taller a la fábrica: proceso de trabajo, industria y clase obrera en la rama del calzado, Buenos Aires 1870-1940. Buenos Aires, Argentina: Ryr.

Koshiro, K. (1987). Personnel planning, technological changes and outsourcing in the Japanese automobile industry: Part 1 \& 2. International Journal of Technology Management, 2(2), 279297. Recuperado de https://www.inderscience.com/info/inarticle. php?artid $=26168$

Luedemann, M. S. (2003). Transformações na indústria automobilística mundial: o caso do complexo automotivo no Brasil 1990-2002 (Tese de Doutorado). Universidade de São Paulo, São Paulo, SP. Recuperado de https://www.teses.usp.br/teses/disponiveis/8/8136/tde-26032012145812/publico/2003_MartadaSilveiraLuedemann.pdf

Marquetti, A., \& Porsse, M. (2014). Patterns of technical progress in the Brazilian economy, 1952-2008. CEPAL Review, 113, 57-73.

Marx, K. (2010). Preface to A Contribution to the Critique of Political Economy. In K. Marx, \& F. Engels (Eds.), Marx \& Engels Collected Works (Vol. 29). London, UK: Lawrence \& Wishart.

Marx, K. (2011). Grundrisse: manuscritos econômicos de 1857-1858; esboços da crítica da economia política. São Paulo, SP: Boitempo Editorial.

Marx, K. (2013). O capital: crítica da economia política; livro primeiro o processo de produção do capital. São Paulo, SP: Boitempo Editorial.

Ministério do Trabalho e Emprego. (2020). Relação Anual de Informações Sociais 1996-2016. Bases Estatísticas RAIS e CAGED. Recuperado de http://bi.mte.gov.br/bgcaged/rais.php

Moraes, B. R., Neto. (1991). Marx, Taylor, Ford: as forças produtivas em discussão (2a ed.). São Paulo, SP: Brasiliense. 
Da manufatura moderna à grande indústria: delimitação empírica da mudança técnica no setor de autoveículos no Brasil (1996-2017)
Elcemir Paço Cunha Lara Nora Portugal Penna Leandro Theodoro Guedes
Moraes, B. R., Neto. (2003). Século XX e trabalho industrial: taylorismo/ fordismo, ohnoísmo e automação em debate. São Paulo, SP: Xamã.

Oliveira, S. L. (2001). Tratado de metodologia científica: projetos de pesquisas, TGI, TCC, monografias, dissertações e teses. São Paulo, SP: Pioneira Thomson Learning.

Paço Cunha, E. (2019). Base técnica e organização do trabalho na manufatura e grande indústria. Verinotio-Revista on-line de Filosofia e Ciências Humanas, 25(1), 41-41.

Pearson, G. S. (2016). The Democratization of Food: Tin Cans and the Growth of the American Food Processing Industry, 1810-1940. Recuperado de https://preserve.lehigh.edu/etd/2756/

Pelaez, V., \& Szmrecsányi, T. (2006). Economia da inovação tecnológica. São Paulo, SP: Editora Hucitec.

Peliano, J. C., Carvalho, R. Q., Sousa, N. H. G., Cassiolato, M.M., Schmitz, H., Gitahy, L., ... Neder, R. T. (1987). Automação e trabalho na indústria automobilística. Brasília, DF: Universidade de Brasília.

Perez, C. (1985). Microelectronics, long waves and world structural change: New perspectives for developing countries. World Development, 13(3), 441-463.

Perez, C. (2011). Finance and technical change: a long-term view: research paper. African Journal of Science, Technology, Innovation and Development, 3(1), 10-35.
Ribeiro, M. A. (1997, outubro 25). Volvo vai montar FH12 no Brasil (p. 2). Jornal do Brasil. Recuperado de http://memoria.bn.br/ DocReader/030015_11/215974

Schmitz, H., \& Carvalho, R. D. Q. (1988). Automação, competitividade e trabalho: a experiência internacional. São Paulo, SP: Editora Hucitec.

Schmitz, H., \& Carvalho, R. Q. (1989). Automation and labour in the Brazilian car industry. Journal of Development Studies, 26(1), 81-119.

Tauile, J. R. (1988). Automação microeletrônica e competitividade: tendências no cenário internacional. In H. Schmitz, \& R. Q. Carvalho (Orgs.), Automação, competitividade e trabalho: a experiência internacional. São Paulo, SP: Hucitec.

Tumolo, P. S. (2001). Reestruturação produtiva no brasil: um balanço crítico introdutório da produção bibliográfica. Educação \& Sociedade, 22(77), 71-99.

Vieira, D. R. (1985). Funções da robótica no processo de acumulação: o caso brasileiro. Petrópolis, RJ: Vozes.

Williams, K., Cutler, T., Williams, J., \& Haslam, C. (1987). The End of Mass Production? Economy and Society, 16(3), 405-439.

Woodward, J. (1980). Industrial organization: theory and practice. Oxford, UK: Oxford University Press. 